\title{
Intake of Fatty Acids in General Populations Worldwide Does Not Meet Dietary Recommendations to Prevent Coronary Heart Disease: A Systematic Review of Data from 40 Countries
}

\author{
Rajwinder K. Harika ${ }^{a} \quad$ Ans Eilander $^{\mathrm{a}} \quad$ Marjan Alssema $^{\mathrm{a}}$ Saskia J.M. Osendarp ${ }^{\mathrm{c}}$ \\ Peter L. Zock ${ }^{a, b}$ \\ a Unilever Research and Development, Vlaardingen, and b Top Institute Food and Nutrition, Wageningen, The \\ Netherlands; ${ }^{\mathrm{C}}$ The Micronutrient Initiative, Ottawa, Ont., Canada
}

\section{Key Words}

Dietary recommendations - Saturated fatty acids .

Polyunsaturated fatty acids $\cdot$ Coronary heart disease

\begin{abstract}
Aim: To systematically review data from different countries on population intakes of total fat, saturated fatty acids (SFA) and polyunsaturated fatty acids (PUFA), and to compare these to recommendations from the Food and Agriculture Organization of the United Nations/the World Health Organization (FAO/WHO). Methods: Data from national dietary surveys or population studies published from 1995 were searched via MEDLINE, Web of Science and websites of national public health institutes. Results: Fatty acid intake data from 40 countries were included. Total fat intake ranged from 11.1 to 46.2 percent of energy intake (\% E), SFA from 2.9 to $20.9 \% \mathrm{E}$ and PUFA from 2.8 to $11.3 \% \mathrm{E}$. The mean intakes met the recommendation for total fat $(20-35 \% \mathrm{E}), \mathrm{SFA}(<10 \%$ E) and PUFA (6-11\% E) in 25, 11 and 20 countries, respectively. SFA intake correlated with total fat intake $(r=0.76, p<$ $0.01)$ but not with PUFA intake $(r=0.03, p=0.84)$. Twentyseven countries provided data on the distribution of fatty acids intake. In 18 of 27 countries, more than $50 \%$ of the population had SFA intakes $>10 \% \mathrm{E}$ and in 13 of 27 countries, the
\end{abstract}

majority of the population had PUFA intakes $<6 \%$ E. Conclusions: In many countries, the fatty acids intake of adults does not meet the levels that are recommended to prevent chronic diseases. The relation between SFA and PUFA intakes shows that lower intakes of SFA in the populations are not accompanied by higher intakes of PUFA, as is recommended for preventing coronary heart disease.

ㄷ) 2013 S. Karger AG, Basel

\section{Introduction}

Reducing saturated fatty acids (SFA) intake is a major focus of most dietary recommendations aiming to prevent chronic diseases including coronary heart disease (CHD). Dietary recommendations by the Food and Agriculture Organization of the United Nations/the World Health Organization (FAO/WHO) [1], Dietary Guidelines for Americans [2,3] and the European Society of Cardiology [4] have set an upper limit of 10 percent of energy intake (\% E) for total SFA intake; for the American Heart Association [5], this upper limit is 7\% E. In addition, recent evidence indicates that SFA reduction alone is not enough to reduce the risk of coronary heart disease (CHD) [6]. There is strong, consistent evidence from randomized clin-

\section{KARGER}

E-Mail karger@karger.com

www.karger.com/anm
(C) 2013 S. Karger AG, Basel

0250-6807/13/0633-0229\$38.00/0
Rajwinder K. Harika

Unilever Research and Development Vlaardingen

Olivier van Noortlaan 120, PO Box 114

NL-3130 AC Vlaardingen (The Netherlands)

E-Mail rajwinder.harika@ unilever.com 
ical trials [7], prospective cohort studies [8] and controlled metabolic studies on blood lipids [9] that reducing dietary SFA and trans fatty acids (TFA) and replacing them with polyunsaturated fatty acids (PUFA) reduces the risk of CHD $[8,10,11]$. Dietary PUFA include vegetable linoleic acid (LA) and alpha linolenic acid (ALA) including long chain PUFA (LCPUFA), eicosapentaenoic acid (EPA) and docosahexaenoic acid (DHA) from marine sources. Therefore, most guidelines on dietary fats indicate that TFA intake should be minimized, consumption of fatty fish should be increased and that SFA should be replaced by (vegetable) PUFA. Recommendations are to consume $<10 \% \mathrm{E}$ as SFA and to consume $6-11 \% \mathrm{E}$ as PUFA $[1,4,12]$.

Despite the well-established fat and fatty acid guidelines, reliable data on their intakes in populations worldwide are scarce. In 2009, Elmadfa and Kornsteiner [12] reviewed fat and fatty acid intakes from 28 countries. They concluded that no general advice could be given for the improvement of fat intake worldwide due to differences in regional intakes. Since this review, new surveys from both developed and developing countries have been published, and international guidelines on fatty acid intakes in adults have been revised [1].

The primary objective of this study was to systematically review the available data on total fat, SFA and PUFA intakes in adults from different countries worldwide and to compare reported intake levels with the FAO/WHOrecommended intake levels to prevent $\mathrm{CHD}$. The additional objective was to assess relations between intake levels of total fat, SFA and PUFA across countries.

\section{Methods}

\section{Search Strategy}

To retrieve information on dietary fat and fatty acid intakes in adults, a literature search in MEDLINE and Web of Science (from 1995 to March 2012) was conducted using the following search string: 'total fat', 'saturated fat*' or SAFA, 'polyunsaturated fat*' or PUFA, 'monounsaturated fat*' or MUFA and 'consumption' or 'intake' or 'survey' and 'adult*' or 'population' as words in the abstract. The reference lists of all articles of interest were checked for additional studies. No language restrictions were used. In addition to the MEDLINE and Web of Science literature search, national intake data were searched via the websites of national public health institutes.

After the initial search, all the publications and reports were screened to determine eligibility of data based on the following inclusion criteria: (1) national survey or population-based studies measuring dietary fatty acid intakes, (2) published later than 1995, (3) data from the general adult population (18-85 years), and (4) complete information provided on intake of total fat and the fatty acids SFA, monounsaturated fatty acids (MUFA) and PUFA and
(5) a sample size $\geq 100$. For countries where multiple datasets were available, data from the most recent national dietary surveys were included. If national dietary surveys were not available, representative data from population-based observational studies were used.

\section{Dietary Recommendations for Intakes of Fatty Acids}

The mean population intakes per country were compared to the recommended intake levels and ranges for total fat and fatty acids for adults as recently determined by the FAO/WHO [1]: total fat $20-35 \%$ E, SFA $<10 \%$ E, PUFA $6-11 \%$ E, (2.5-9\% E of which were omega- 6 (LA) and $0.5-2 \%$ E were omega- 3 fatty acids (ALA)), and EPA + DHA 0.250-2 g/day.

\section{Data Extraction and Statistical Analysis}

From each data source, we extracted the means and, when reported, standard deviations (SD) of intakes of total fat, SFA, MUFA and PUFA. Where fat and fatty acid intakes were expressed as absolute amounts (grams per day), values were converted to percentages of total energy intake using the conversion factor of $37.7 \mathrm{~kJ} / \mathrm{g}$ for fat and fatty acid.

Where data were reported for subgroups (for example by age range or by gender), a weighted mean was calculated by weighing the mean intake of each subgroup by the number of the subjects in the subgroup. When SDs were not reported, they were calculated using the population sample size and reported standard error of mean (SEM).

The percentage of adults from each country deviating from the recommended intake for SFA and PUFA were estimated using the reported mean $(\mu)$ and $S D$, assuming a normal distribution of the data. The following formula was used to calculate $\mathrm{z}$ scores: $\mathrm{z}$ score $=$ $[\mathrm{X}-\mu] / \mathrm{SD}$. A normal distribution probability table [13] was used to derive the $\mathrm{p}$ values, i.e. the probability of deviating from the recommended intake or limit $\mathrm{X}$, for example, $10 \%$ of SFA. This $\mathrm{p}$ value corresponding with limit X multiplied by 100 gives the percentage of the population that can be expected to be above or below limit X.

Pearson correlations between total fat, SFA and PUFA were computed. Statistical analyses were conducted using the Predictive Analytics software program (release 18.0.2, Chicago, Ill., USA).

\section{Results}

\section{Availability of Data}

The initial literature search yielded 651 publications and reports, 67 of which met the inclusion criteria for potentially eligible data sources (fig. 1). In a subsequent selection step, 24 data sources were excluded for the following reasons: (1) multiple surveys from the same country $(\mathrm{n}=20$; in these cases only the most recent data sets were used), (2) incomplete information on fatty acid intakes $(\mathrm{n}=1)$, (3) surveys only reporting data of specific ethnic or minority groups in the population $(n=1),(4)$ studies that included diseased subjects $(n=1)$ and $(5)$ a sample size $<100$ subjects $(\mathrm{n}=1)$. 


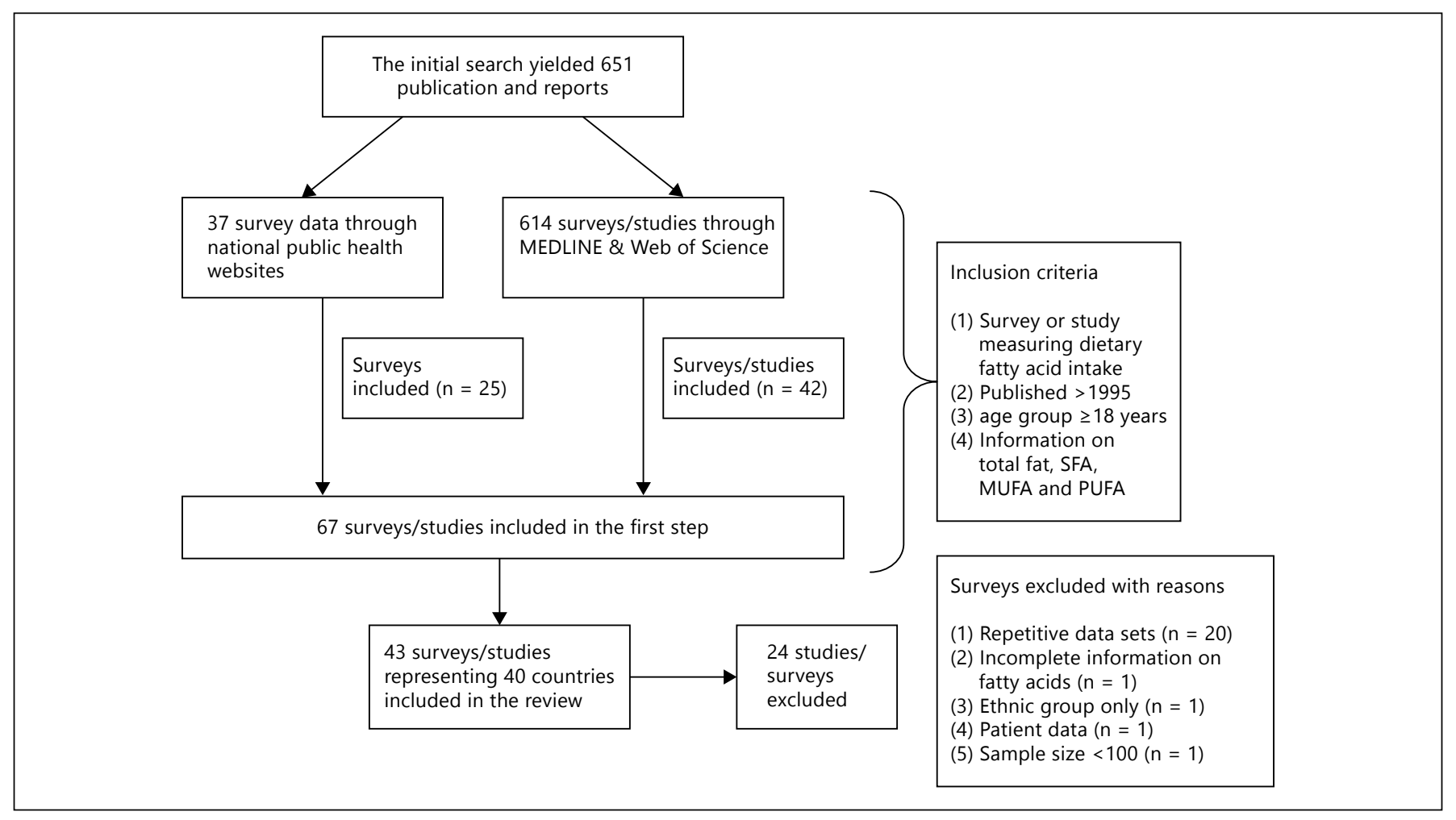

Fig. 1. Selection procedure and number of surveys and studies included and excluded from the review.

In total, 43 datasets met the inclusion criteria (fig. 1) representing 40 countries. For three countries, Australia, Belgium and Germany, two separate data sets reported intake data in SFA, MUFA and PUFA and data on omega-6/LA and omega-3/ALA. Details on surveys and studies included for review are given in table 1.

For 27 of 40 countries which provided information on distribution of the data, we could estimate the percentages of the population that failed to meet the recommended intakes for SFA and PUFA. For the remaining 13 countries (Austria, Australia, Cameroon, Finland, France, Indonesia, Japan, Netherlands, New Zealand, Norway, Slovakia, Slovenia and Spain), these could not be estimated because a SD or other measure of the population distribution was not reported.

Reported Intakes of Total Fat and Fatty Acids and Differences from Recommended Intake Levels

Total Fat

Mean intake of total fat ranged across countries from 11.1 to $46.2 \% \mathrm{E}$ (table 1), with the lowest intake reported in Bangladesh and the highest intake reported in Greece. In 25 of the 40 countries, the mean total fat intakes were within the recommended range of $20-35 \%$ E. Of the re- maining 15 countries, 14 had a mean total fat intake $>35 \% \mathrm{E}$ and one country had a mean total fat intake $<20 \%$ E (Bangladesh: 11\% E).

\section{SFA}

Mean intake of SFA ranged from 2.9 to $20.9 \% \mathrm{E}$ across countries, with the lowest intake reported in Bangladesh and the highest intake in Indonesia (table 1). In 11 of the 40 countries, the mean SFA intakes were within the $\mathrm{FAO} / \mathrm{WHO}$ recommended intake of $<10 \% \mathrm{E}$ (fig. 2).

In 18 of 27 countries for which we could estimate the population percentages deviating from recommended intakes, $50-96 \%$ of the population had SFA intakes $>10 \% \mathrm{E}$ (fig. 3). The percentage of population exceeding the recommended 10\% E SFA intakes was lowest in five Asian countries: $0 \%$ for Bangladesh, $1 \%$ for China, $16 \%$ for Hong Kong, 16\% for South Korea and 17\% for India.

\section{PUFA}

Mean intakes of PUFA ranged from 2.8 to $11.3 \% \mathrm{E}$ (table 1). In 20 of 40 countries, PUFA intakes were within the $\mathrm{FAO} / \mathrm{WHO}$ recommended range of $6-11 \% \mathrm{E}$ (fig. 2).

In 13 of 27 countries for which we could estimate the population percentages deviating from recommended in- 
Table 1. Mean \pm SD intakes of total fat, SFA, MUFA and PUFA among adults in 40 countries

\begin{tabular}{|c|c|c|c|c|c|c|c|c|c|}
\hline $\begin{array}{l}\text { Country and } \\
\text { Reference }\end{array}$ & Year & Data source & $\begin{array}{l}\text { Sample } \\
\text { size }\end{array}$ & Dietary method & $\begin{array}{l}\text { Energy, } \\
\text { kJ } \\
\text { Mean }\end{array}$ & $\begin{array}{l}\text { Total fat, } \\
\% \text { E } \\
\text { Mean } \pm \text { SD }\end{array}$ & $\begin{array}{l}\text { SFA, } \\
\% \mathrm{E} \\
\text { Mean } \pm \text { SD }\end{array}$ & $\begin{array}{l}\text { MUFA, } \\
\% \text { E } \\
\text { Mean } \pm \text { SD }\end{array}$ & $\begin{array}{l}\text { PUFA, } \\
\% \text { E } \\
\text { Mean } \pm \text { SD }\end{array}$ \\
\hline Australia [14] & 1998 & national nutrition survey & 8,891 & 24-hour recall and FFQ & 9,237 & 32.5 & 12.7 & 11.8 & 5.0 \\
\hline Austria [15] & 2009 & Austrian Nutrition Survey 2008 & 2,123 & 24-hour recall & 8,242 & 37.0 & 14.5 & 12.5 & 8.0 \\
\hline Bangladesh*[16] & 2004 & prospective cohort study & 189 & 7-day food diary & 9,506 & $11.1 \pm 3.2$ & $2.9 \pm 1.2$ & $3.8 \pm 1.2$ & $2.8 \pm 0.7$ \\
\hline Belgium [17] & 2006 & $\begin{array}{l}\text { Nutrition and Health (BIRNH) } \\
\text { Survey }\end{array}$ & 3,245 & $2 \times 24$-hour recall and FFQ & - & $37.5 \pm 6.4$ & $15.6 \pm 3.6$ & $13.8 \pm 2.5$ & $6.8 \pm 2.4$ \\
\hline Bulgaria [18] & 1998 & national nutrition survey & 860 & 24-hour recall & 9,953 & $34.6 \pm 8.6$ & $12.5 \pm 5.5$ & $9.9 \pm 3.2$ & $11.3 \pm 4.6$ \\
\hline Cameroon [19] & 2000 & habitual diet study & 1,785 & FFQ & 15,857 & 42.7 & 14.3 & 16.7 & 6.0 \\
\hline Canada [20] & 2004 & nutrition survey & 18,820 & 24-hour recall & 8,645 & $31.4 \pm 17.0$ & $10.2 \pm 9.3$ & $12.5 \pm 9.3$ & $5.6 \pm 4.6$ \\
\hline China [21] & 2003 & $\begin{array}{l}\text { INTERMAP (cross-sectional) } \\
\text { study }\end{array}$ & 839 & four 24-hour recall & 8,583 & $20.0 \pm 6.1$ & $5.0 \pm 2.0$ & $8.1 \pm 2.8$ & $5.8 \pm 2.2$ \\
\hline Czech Republic [22] & 2010 & The HAPIEE study & 7,913 & FFQ & 8,443 & $36.0 \pm 15.0$ & $13.0 \pm 5.7$ & $13.0 \pm 5.5$ & $7.0 \pm 2.9$ \\
\hline Denmark [23] & 2010 & national dietary survey & 3,151 & 7-day food record & 9,200 & $35.0 \pm 5.6$ & $15.0 \pm 3.0$ & $12.0 \pm 2.4$ & $5.0 \pm 1.0$ \\
\hline Finland [24] & 2008 & national nutrition survey & 1,594 & 48-hour recall & 7,917 & $32.1 \pm 7.6$ & $13.5 \pm 4.4$ & $12.4 \pm 3.7$ & $6.2 \pm 2.4$ \\
\hline France [25] & 2004 & dietary survey & 1,089 & 7-day record & 9,108 & 37.2 & 14.1 & 11.8 & 3.9 \\
\hline Germany [26] & 2004 & German Nutrition Survey & $>1,000$ & written diet record & 10,292 & 35.9 & 14.4 & 12.8 & 6.5 \\
\hline Greece [27] & 2004 & Greek EPIC cohort & 20,942 & FFQ & 9,393 & $46.2 \pm 5.3$ & $13.1 \pm 2.7$ & $22.3 \pm 4.0$ & $6.6 \pm 2.6$ \\
\hline Guatemala [28] & 2009 & cross-sectional study & 1,220 & FFQ & 12,422 & $22.6 \pm 7.0$ & $9.1 \pm 4.2$ & $7.7 \pm 2.1$ & $4.3 \pm 0.9$ \\
\hline Hong Kong [29] & 1997 & $\begin{array}{l}\text { dietary survey in } \\
\text { cardiovascular risk factor study }\end{array}$ & 1,010 & FFQ & 8,853 & $29.0 \pm 5.5$ & $8.0 \pm 2.0$ & $10.2 \pm 5.6$ & $6.5 \pm 1.5$ \\
\hline Hungary [30] & 2011 & national dietary survey & 3,077 & 3-day dietary record & 10,263 & $37.5 \pm 5.5$ & $10.7 \pm 2.4$ & $11.3 \pm 2.7$ & $8.9 \pm 2.2$ \\
\hline $\operatorname{India}^{\dagger}[31]$ & 2006 & cross-sectional study & 102 & FFQ & 10,903 & $22.5 \pm 6.9$ & $7.2 \pm 2.9$ & $8.7 \pm 2.5$ & $6.6 \pm 2.1$ \\
\hline Indonesia [32] & 2005 & cross-sectional study & 1,430 & 24-hour recall & 5,958 & 31.9 & 20.9 & 5.2 & 3.5 \\
\hline Ireland [33] & 2008 & food consumption survey & 1,097 & 7-day food diary & - & $35.8 \pm 5.4$ & $14 \pm 3.1$ & $12.0 \pm 2.0$ & $7.0 \pm 2.1$ \\
\hline Israel [34] & 2001 & $\begin{array}{l}\text { MABAT First Israeli National Health } \\
\text { and Nutrition Survey }\end{array}$ & 3,242 & $\begin{array}{l}\text { 24-hour recall and } \\
\text { questionnaire }\end{array}$ & 7,770 & $33.0 \pm 9.0$ & $9.0 \pm 4.0$ & $11.0 \pm 5.0$ & $8.0 \pm 4.0$ \\
\hline Italy [35] & 2000 & nutrition survey & 1,461 & 7-day dietary record & 10,292 & $35.0 \pm 6.0$ & $10.6 \pm 2.4$ & $12.8 \pm 3.6$ & $4.8 \pm 2.2$ \\
\hline Japan [36] & 2004 & national nutrition survey & $>1,000$ & $\begin{array}{l}\text { diet record and food } \\
\text { weight record for } 1 \text { day }\end{array}$ & - & 25.3 & 8.4 & 9.4 & 7.5 \\
\hline Malaysia [37] & 2011 & cross-sectional study & 151 & 3-day dietary record & 7,644 & $32.8 \pm 5.2$ & $10.1 \pm 2.9$ & $8.5 \pm 2.3$ & $5.3 \pm 1.9$ \\
\hline Mexico [38] & 2011 & $\begin{array}{l}\text { Mexican Health and Nutrition Survey, } \\
2006\end{array}$ & 16,366 & FFQ & 6,924 & $25.1 \pm 17.0$ & $9.9 \pm 7.6$ & $8.9 \pm 6.3$ & $6.3 \pm 5.0$ \\
\hline The Netherlands [39] & 2011 & $\begin{array}{l}\text { Dutch National Food } \\
\text { Consumption Survey }\end{array}$ & 2,106 & 24-hour recalls & 9,287 & 34.9 & 13.1 & 12.0 & 6.8 \\
\hline New Zealand [40] & 2011 & national nutrition survey & 4,721 & 24-hour recall & 9,096 & 33.7 & 13.1 & 12.4 & 4.9 \\
\hline Norway [41] & 1997 & $\begin{array}{l}\text { Norwegian National } \\
\text { Nutrition Surveys }\end{array}$ & 2,672 & FFQ & 9,399 & 30.6 & 12.1 & 10.8 & 5.4 \\
\hline Poland [42] & 2003 & $\begin{array}{l}\text { household food } \\
\text { consumption survey }\end{array}$ & 2,893 & 24-hour recall & - & $35.7 \pm 8.1$ & $11.6 \pm 4.1$ & $15.4 \pm 4.5$ & $5.2 \pm 2.4$ \\
\hline Portugal [43] & 1999 & cross-sectional study & 489 & FFQ & 9,690 & $28.5 \pm 5.0$ & $8.9 \pm 2.4$ & $12.4 \pm 2.4$ & $4.9 \pm 1.1$ \\
\hline Russia [22] & 2010 & The HAPIEE study & 9,098 & FFQ & 10,790 & $43.0 \pm 15.0$ & $14.0 \pm 6.2$ & $16 \pm 6.1$ & $9.0 \pm 3.5$ \\
\hline Singapore [44] & 2004 & national nutrition survey & 1,278 & 24-hour recall & 10,033 & $29.6 \pm 10.0$ & $11.2 \pm 3.5$ & $9.8 \pm 3.6$ & $5.6 \pm 3.5$ \\
\hline Slovakia [45] & 2002 & two epidemiologic studies & 4,018 & 24-hour recall & - & 35.5 & 13.0 & 11.9 & 8.7 \\
\hline Slovenia [46] & 1999 & epidemiological study & 2,183 & FFQ & 11,422 & 44.3 & 14.8 & 13.0 & 3.9 \\
\hline Spain [27] & 2005 & $\begin{array}{l}\text { large studies (pooled analysis } \\
\text { of studies) 1990-1998 }\end{array}$ & 10,208 & $\begin{array}{l}24 \text {-hour diet, 3-day diet } \\
\text { record and FFQ }\end{array}$ & 9,142 & 38.5 & 12.0 & 15.9 & 5.6 \\
\hline South Africa ${ }^{\ddagger}$ [47] & 2002 & cross-sectional study & 292 & $\begin{array}{l}\text { validated } \\
\text { quantitative FFQ }\end{array}$ & 8,010 & $27.7 \pm 9.4$ & $8.6 \pm 4.8$ & $9.5 \pm 4.8$ & $6.9 \pm 3.7$ \\
\hline South Korea [48] & 2004 & dietary intake study & 224 & 3-day dietary record & 7,610 & $21.1 \pm 14.0$ & $5.9 \pm 4.2$ & $7.7 \pm 6.0$ & $5.0 \pm 3.7$ \\
\hline Sweden [49] & 2005 & national food survey & 1,217 & $\begin{array}{l}\text { precoded } 7 \text {-day food } \\
\text { record questionnaire }\end{array}$ & 8,891 & $34.0 \pm 5.0$ & $14.5 \pm 2.5$ & $12.5 \pm 2.0$ & $4.7 \pm 1.4$ \\
\hline UK [50] & 2012 & national diet and nutrition survey & 434 & $\begin{array}{l}\text { 4-day estimated food } \\
\text { diary }\end{array}$ & 7,543 & $32.9 \pm 7.0$ & $12.0 \pm 3.4$ & $11.7 \pm 3.0$ & $5.9 \pm 2.0$ \\
\hline USA [51] & 2010 & $\begin{array}{l}\text { NHANES nutrition survey } \\
(2007-2008)\end{array}$ & 5,420 & 2 diet recall & 8,903 & $34.0 \pm 14$ & $11.0 \pm 7.3$ & $12.5 \pm 7.3$ & $7.0 \pm 7.3$ \\
\hline
\end{tabular}

* Only data reported with food diaries included.

† Only baseline data from FFQ1 included.

‡ Only data included from middle-class urban population. 


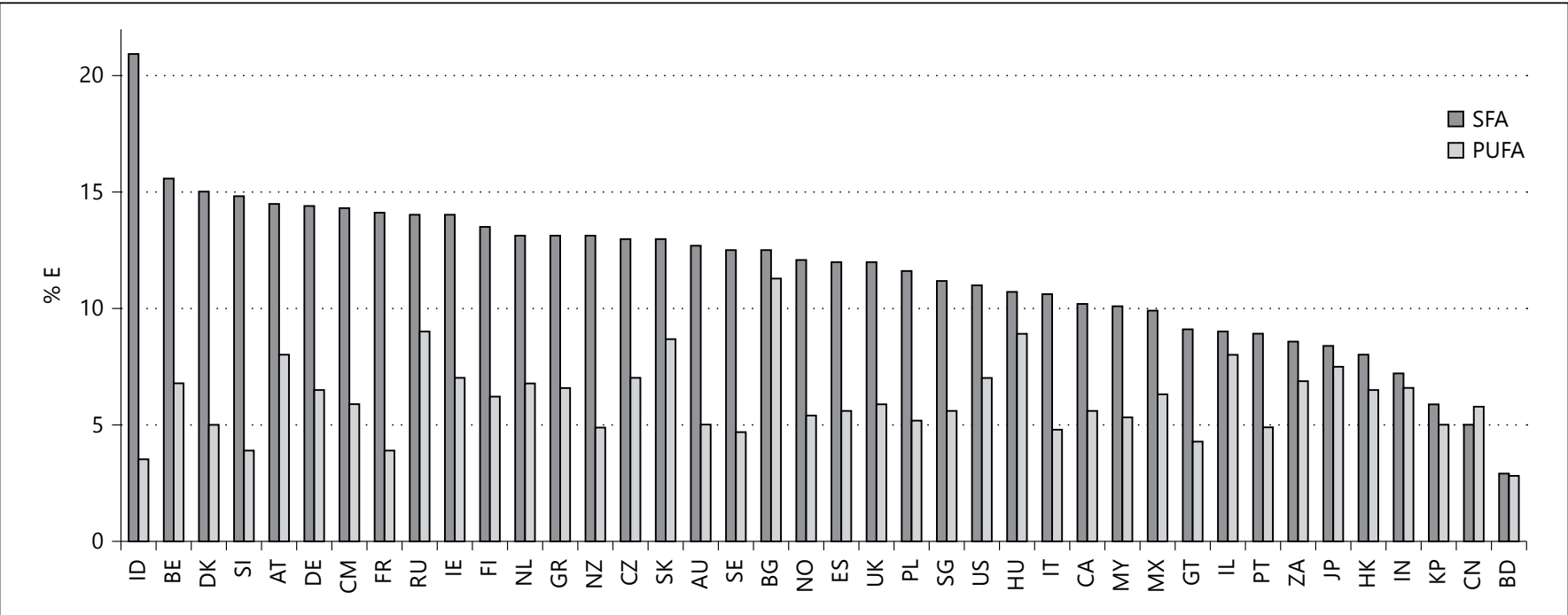

Fig. 2. Mean intake of SFA (intake in descending order) and PUFA in 40 countries. ID = Indonesia; $\mathrm{BE}=$ Belgium; $\mathrm{DK}=$ Denmark; $\mathrm{SI}=$ Slovenia; $\mathrm{AT}=$ Austria $\mathrm{DE}=$ Germany; $\mathrm{CM}=$ Cameroon; $\mathrm{FR}=$ France RU = Russia; $\mathrm{IE}=$ Ireland $; \mathrm{FI}=$ Finland $\mathrm{NL}=$ Netherlands; GR = Greece; NZ = New Zealand; CZ = Czech Republic; $\mathrm{SK}=$ Slovakia; $\mathrm{AU}=$ Australia; $\mathrm{SE}=$ Sweden; $\mathrm{BG}=$
Bulgaria $; \mathrm{NO}=$ Norway; $\mathrm{ES}=$ Spain $\mathrm{UK}=$ United Kingdom $; \mathrm{PL}=$ Poland; SG = Singapore; US = United States; HU = Hungary; IT = Italy; $\mathrm{CA}=$ Canada $\mathrm{MY}=$ Malaysia; $\mathrm{MX}=$ Mexico $\mathrm{GT}=$ Guatemala; $\mathrm{IL}=$ Israel; PT = Portugal; ZA = South Africa; JP = Japan; HK = Hong Kong; IN = India; $\mathrm{KP}=$ South Korea; $\mathrm{CN}=$ China; $\mathrm{BD}=$ Bangladesh.

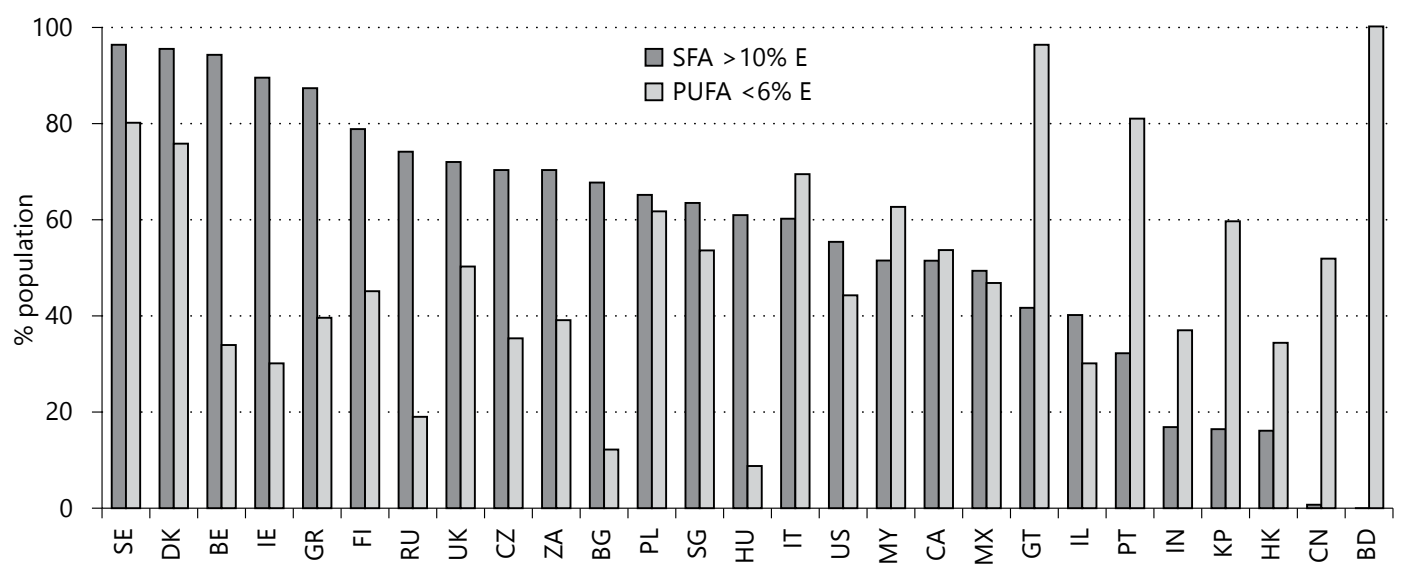

Fig. 3. Percentage of population consuming higher SFA $(>10 \% \mathrm{E})$ and lower PUFA $(<6 \% \mathrm{E})$ than recommended. SE $=$ Sweden; $\mathrm{DK}=$ Denmark; BE = Belgium; IE = Ireland; GR = Greece; FI = Finland; $\mathrm{RU}=$ Russia; $\mathrm{UK}=$ United Kingdom; $\mathrm{CZ}=$ Czech Republic; $\mathrm{ZA}=$ South Africa; $\mathrm{BG}=$ Bulgaria $\mathrm{PL}=$ Poland; $\mathrm{SG}=$ Singapore; $\mathrm{HU}=$

takes, $50-100 \%$ of the population had PUFA intakes that were $<6 \% \mathrm{E}$ (fig. 3 ). The percentage of population not reaching the recommended PUFA intake range was lowest in three European countries: 9\% for Hungary, $12 \%$ for Bulgaria and 19\% for Russia.

Fatty Acid Intake vs. Recommendations
Hungary; IT = Italy; US = United States; MY = Malaysia; CA = Canada; $\mathrm{MX}=$ Mexico; GT = Guatemala IL = Israel; $\mathrm{PT}=$ Portugal; $\mathrm{IN}=$ India; $\mathrm{KP}=$ South Korea; $\mathrm{HK}=$ Hong Kong; $\mathrm{CN}=$ China; $\mathrm{BD}=$ Bangladesh .

\section{Separate Fatty Acids}

For 15 of the 40 countries, additional data on omega-6/ LA and omega-3/ALA were available as well as on LCPUFA, EPA and DHA for six countries (table 2). In this subset of countries, reported mean intakes of ALA 
Table 2. Mean \pm SD intakes of PUFA, LA, ALA, EPA and DHA in 15 countries

\begin{tabular}{|c|c|c|c|c|c|c|}
\hline Country & Reference & $\begin{array}{l}\text { PUFA, \% E } \\
\text { mean } \pm S D\end{array}$ & $\begin{array}{l}\mathrm{LA}, \% \mathrm{E} \\
\text { mean } \pm \mathrm{SD}\end{array}$ & $\begin{array}{l}\mathrm{ALA}, \% \mathrm{E} \\
\text { mean } \pm \mathrm{SD}\end{array}$ & $\begin{array}{l}\mathrm{EPA}, \\
\mathrm{mg}\end{array}$ & $\begin{array}{l}\text { DHA, } \\
\text { mg }\end{array}$ \\
\hline Australia & {$[52]$} & 5.0 & 4.4 & 0.5 & 56 & 106 \\
\hline Belgium & {$[53,54]$} & $6.8 \pm 2.4$ & $5.5 \pm 1.7$ & $0.6 \pm 0.3$ & & 190 \\
\hline China & [21] & $5.8 \pm 2.2$ & $5.3 \pm 2.1$ & $0.6 \pm 0.4$ & - & - \\
\hline Finland & {$[24]$} & $6.2 \pm 1.0$ & $3.9 \pm 1.7$ & $1.0 \pm 0.5$ & - & - \\
\hline Germany & {$[55]$} & 6.5 & 5.6 & 0.8 & - & - \\
\hline Hungary & {$[30]$} & $8.9 \pm 2.2$ & $8.6 \pm 3.2$ & $0.3 \pm 0.2$ & - & - \\
\hline Israel & [34] & $8.0 \pm 4.0$ & $7.4 \pm 5.8$ & $0.8 \pm 0.8$ & - & - \\
\hline Japan & [36] & 7.5 & 6.1 & 0.8 & 42 & 64 \\
\hline Mexico & [38] & $6.3 \pm 5.0$ & $3.1 \pm 2.5$ & $0.02 \pm 1.2$ & - & - \\
\hline The Netherlands & [39] & 6.8 & 5.6 & 0.7 & 178 & \\
\hline Slovakia & {$[45]$} & 8.7 & 7.9 & 0.5 & - & - \\
\hline South Korea & {$[48]$} & $5.0 \pm 3.7$ & $4.0 \pm 3.1$ & $0.4 \pm 0.6$ & 215 & 204 \\
\hline Sweden & [49] & $4.7 \pm 1.4$ & 3.7 & 0.6 & - & - \\
\hline UK & {$[50]$} & $5.9 \pm 2.0$ & $4.9 \pm 1.5$ & $1.0 \pm 0.5$ & - & - \\
\hline USA & [51] & $7.0 \pm 7.3$ & $6.4 \pm 9.5$ & $0.6 \pm 1.0$ & 49 & 80 \\
\hline
\end{tabular}

ranged from 0.02 to $1 \% \mathrm{E}$, and were within the recommended range of $0.5-2 \% \mathrm{E}$ in all countries except for Mexico $(0.02 \%$ E), Hungary $(0.3 \%$ E) and South Korea $(0.4 \% \mathrm{E})$. Mean intakes of LA ranged from 3.1 to $8.6 \% \mathrm{E}$, and intakes for all countries reporting data were within the recommended range of 2.5-9\% E. Mean intakes of EPA plus DHA varied between 106 and 419 milligrams per day, and were below the recommended intake level of $250 \mathrm{mg} /$ day in five of six countries (table 2).

\section{Relationships between Intakes of Fat and Fatty Acids within Countries}

Figure 4 shows the relationships between intakes of total fat, SFA and PUFA, based on their mean intakes in 40 countries. Total fat was significantly correlated with SFA intakes $(\mathrm{r}=0.76, \mathrm{p}<0.01$; fig. $4 \mathrm{a})$ but not with PUFA intakes $(r=0.27, p=0.09$; fig. $4 b)$. Intakes of SFA and PUFA were not correlated either $(\mathrm{r}=0.03, \mathrm{p}=0.84$; fig. 4c).

\section{Discussion}

This review demonstrates that in the majority of countries reporting fat and fatty acid intakes, the average SFA intake is higher than the recommended maximum of $10 \%$ $\mathrm{E}$ while in half of the countries, average PUFA intake is lower than the recommended range of $6-11 \% \mathrm{E}$. The lack of correlation between SFA and PUFA intakes across countries indicates that lower SFA intakes generally do not go together with higher PUFA intakes, the preferred replacement of SFA to prevent CHD.

Few papers have reported data on average fat and fatty acid intakes in different countries $[12,56,57]$. However, to our knowledge, our paper is the first to use a systematic approach to review the available data on fat intakes of different adult populations around the world, and to compare the reported intakes with the most recent recommended intake levels to prevent CHD [1]. In addition, our review addressed the population distributions of fatty acid intakes and the relations between intakes of total fat, SFA and PUFA at the population level. Several limitations of our analysis should be considered when interpreting the results within individual countries and making comparisons between countries. The main limitation is the heterogeneity of the available data sources with respect to the sampling and dietary assessment methods; this contributes to observed differences between countries. For example, national dietary surveys are the preferred type of research to estimate the distribution of nutrient intake in populations. These were available for the majority (24 out of 40 ) of the countries. However, it should be realized that national dietary surveys have limitations as well. Data from large observational studies were used for the remaining 16 countries. These data may not always be representative of national intakes, in particular for countries such as India and Malaysia where the data were based on a small sample size $(<150)$ from one city only. Data for half of the countries in this review were based on weighed food records (for 3-7 days), multiple 


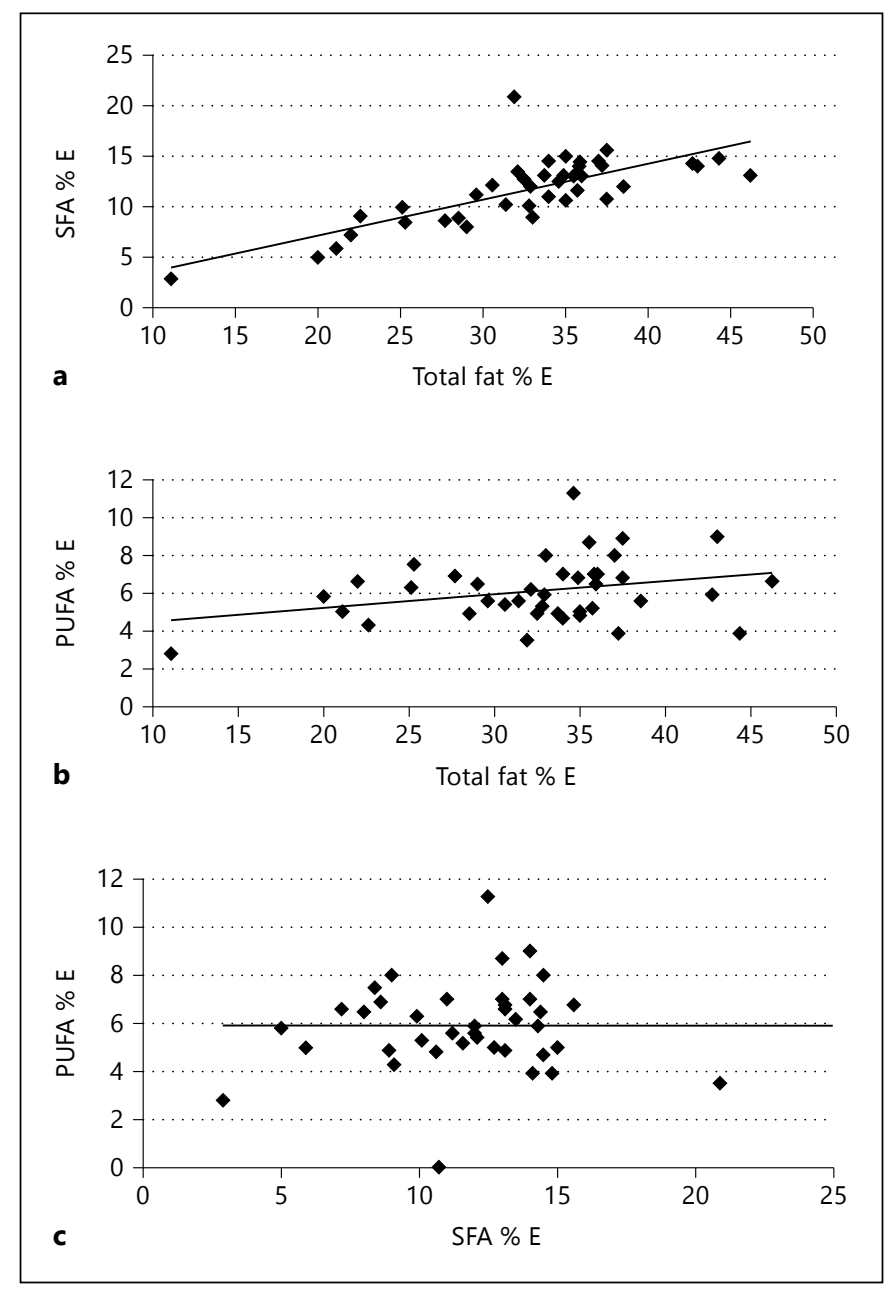

Fig. 4. Scatter plots on relationships between total fat and SFA intakes $\left[y=-0.10+0.35 x ; r^{2}=0.56\right](\mathbf{a})$, total fat and PUFA intakes $\left[\mathrm{y}=3.72+0.07 \mathrm{x} ; \mathrm{r}^{2}=0.09\right](\mathbf{b})$ and SFA and PUFA intakes $[\mathrm{y}=$ $\left.5.73+0.03 x ; r^{2}=0.00\right](\mathbf{c})$.

24-hour dietary recalls and 24-hour dietary recalls that were combined with food frequency questionnaires (FFQ). This combination of dietary assessment methods is considered more reliable for estimating the usual intake of foods in individuals than only single FFQs or 24-hour recalls [58-60], which were the basis for data from the remaining countries. Thus, we cannot exclude that differences in reported intakes between countries is partly due to differences in the data collection methods.

The second important limitation is incomplete information on specific fatty acids for some foods in local food composition tables [61], which could easily lead to underestimation of true intakes of SFA, MUFA or PUFA. For example, the sum of SFA, MUFA and PUFA is lower than that of total fat in 37 of 40 countries. Such differences are also found in other studies $[12,56,57]$. However, for 7 countries, this gap was larger than 5\% E (Hungary, 5.2\% E, Cameroon 5.8\% E, France 7.4\% E, Italy 6.8\% E, Malaysia $8.9 \% \mathrm{E}$ and Slovenia $12.6 \% \mathrm{E})$. A larger difference between total fat and the sum of SFA, MUFA and PUFA could indicate that a higher number of foods in the food composition table are without values for fatty acids. Therefore, results for total fat are more reliable than for separate fatty acid classes in these countries.

Third, fatty acid intakes data are reported for a limited number of countries worldwide. While data are available for most developed regions, much less data are available for Asia, Africa and South America.

Finally, we assumed a normal distribution of population intakes to estimate the percentages of adults not meeting the recommendations for SFA and PUFA. For developed countries, this seems a valid assumption because intakes of fat and fatty acids are usually normally distributed, even when there are differences in intakes between regions or socioeconomic strata $[62,63]$. However, for developing countries such as India or Indonesia, the variability in fat intake can for a large part depend on the region and income level $[32,64,65]$. As a result, the distribution of the data may be skewed or bimodal in these countries. Thus, our estimations of the percentages of people deviating from recommended intake levels may be more reliable for developed countries than for developing countries. Because of these limitations, interpretation of results within individual countries and comparisons between countries should be made with care.

Our findings are consistent with earlier studies on fat and fatty acid intakes in adults $[12,56,57]$ and children [66], indicating that in many countries, SFA intakes are higher and PUFA intakes are lower than recommended. Similarly, Elmadfa and Kornsteiner [12] showed that in 20 out of 28 countries worldwide, SFA intakes were higher than the recommended maximum intake of $10 \% \mathrm{E}$, and that PUFA intakes were lower than the recommended range of $6-11 \%$ E. High SFA and low PUFA intakes in Europe were also found in the TRANSFAIR study and in the European Prospective Investigation into Cancer and Nutrition study (EPIC) [56, 57]. TRANSFAIR reported SFA intakes ranging from 10 to $19 \% \mathrm{E}$ and PUFA intakes ranging from 3 to 7\% E [56] and EPIC reported SFA intakes of $9-16 \% \mathrm{E}$ and PUFA intakes of $4-8 \% \mathrm{E}$ in different countries [57].

The relatively large contribution of SFA to total energy in developed countries is likely due to high intakes of SFA-rich foods such as meat and dairy products $[24,40$, $50,67]$. Our results show that a large percentage of the 
populations in Asian countries (Bangladesh, China, Hong Kong, South Korea and India) have SFA intakes below the recommended maximum of $10 \% \mathrm{E}$. These lower SFA intakes tend to go together with lower total fat intakes, as the variation in total fat intake explained more than half (56\%) of the variance in SFA intake across countries. In contrast, mean PUFA intakes seem to be much less dependent on total fat intake ( $<10 \%$ of variance explained); they were at the lower end of the recommended range $(6 \%$ E) in countries with the highest total fat intakes $(>35 \% \mathrm{E})$ such as Spain, Slovenia and France. Thus, the differences in PUFA intakes between countries are apparently not driven by differences in total fat intakes, but more likely due to differences in local food habits and types and amounts of cooking oils and fats used. For example, greater use of sunflower oils in Bulgaria is known to contribute to the relatively high PUFA intake (in particular, linoleic acid) in this country [18]. On the other hand, the common use of butter and animal fats for cooking in many Western countries $[67,68]$, coconut oil in Indonesia and palm oil in Cameroon are important contributors to both low PUFA and high SFA intakes $[19,32]$. Thus, it is likely that a major part of the variation in reported intakes between populations reflects the true underlying differences in intakes and type of fats and oils consumed.

Lowering the intake of SFA and replacing it with PUFA can have a substantial impact on the incidence of CHD in the population [7]. Practical examples of the public health impact are provided by experiences in Finland and Poland, where replacement of SFA by PUFA in the population has been associated with a significant decline in CHD mortality $[69,70]$. However, our data show that a lower SFA intake does not necessarily go together with a higher PUFA intake, but is apparently compensated by higher intakes of other macronutrients. For example, in the USA, the contribution of total fat to energy intake decreased in the last decades but at the same time, the contribution of carbohydrates in the form of sugars and refined carbohydrates has increased, which does not confer benefit for CHD prevention $[71,72]$. Public health messages and dietary policies should emphasize the replacement of SFA by PUFA instead of 'low-fat diet' or 'dietary fat should be consumed sparingly', as such messages may not guide the general population towards replacing SFA by PUFA [73] as is recommended by the FAO/WHO to prevent CHD [1].

Despite the general recognition of the importance of dietary fats in improving public health, our review shows that reliable data on intakes of fatty acid are scarce. Adequate data are needed to establish and support effective public health policies. This is of particular importance for developing countries, where diets are rapidly becoming more atherogenic, and the incidence of CHD is increasing [74].

In conclusion, the available data indicate that in many countries, adults have higher SFA and lower PUFA intakes than what is recommended. Lower intakes of SFA in the populations are not accompanied by higher intakes of PUFA, as recommended to prevent CHD. These data reinforce the need to focus public health campaigns on the replacement of foods and fats rich in SFA with those rich in PUFA, especially in countries with high SFA intakes. For developing countries with low total fat and SFA intakes, an increase in total fat intake should be in the form of PUFA rather than SFA.

\section{Acknowledgements}

We would like to thank Peter van Bruggen for statistical input and other Unilever colleagues for helping identify dietary data sources from national public health institutes.

\section{Disclosure Statement}

RKH, MA, EA \& PLZ are employees of Unilever. Unilever markets food products made of vegetable oils, including margarines and dressings.

\section{References}

1 FAO/WHO: WHO: Fats and fatty acids in human nutrition. Report of an expert consultation. Food and Nutrition Paper. Food and Agriculture Organisation of the United Nations, Rome, 2010.

-2 Kris-Etherton PM, Innis S, Ammerican DA, Dietitians of Canada: Position of the American Dietetic Association and Dietitians of Canada: dietary fatty acids. J Am Diet Assoc 2007;107: 1599-1611.
3 U.S. Department of Agriculture, U.S. Department of Health and Human Services: Dietary Guidelines for Americans, 2010.

-4 Perk J, De BG, Gohlke H, Graham I, Reiner Z, Verschuren M, Albus C, Benlian P, Boysen G, Cifkova R, Deaton C, Ebrahim S, Fisher M, Germano G, Hobbs R, Hoes A, Karadeniz S, Mezzani A, Prescott E, Ryden L, Scherer M, Syvanne M, Scholte op Reimer WJ, Vrints C, Wood D, Zamorano JL, Zannad F: European Guidelines on cardiovascular disease prevention in clinical practice (version 2012). The Fifth Joint Task Force of the European Society of Cardiology and Other Societies on Cardiovascular Disease Prevention in Clinical Practice (constituted by representatives of nine societies and by invited experts). Developed with the special contribution of the European Association for Cardiovascular Prevention \& Rehabilitation (EACPR). Eur Heart J 2012;33:1635-1701. 
5 Lichtenstein AH, Appel LJ, Brands M, Carnethon M, Daniels S, Franch HA, Franklin B, Kris-Etherton P, Harris WS, Howard B, Karanja N, Lefevre M, Rudel L, Sacks F, Van HL, Winston M, Wylie-Rosett J: Diet and lifestyle recommendations revision 2006: a scientific statement from the American Heart Association Nutrition Committee. Circulation 2006;114:82-96.

6 Siri-Tarino PW, Sun Q, Hu FB, Krauss RM: Meta-analysis of prospective cohort studies evaluating the association of saturated fat with cardiovascular disease. Am J Clin Nutr 2010;91:535-546.

7 Mozaffarian D, Micha R, Wallace S: Effects on coronary heart disease of increasing polyunsaturated fat in place of saturated fat: a systematic review and meta-analysis of randomized controlled trials. PLoS Med 2010; 7:e1000252.

$\$ 8$ Jakobsen MU, O’Reilly EJ, Heitmann BL, Pereira MA, Balter K, Fraser GE, Goldbourt U, Hallmans G, Knekt P, Liu S, Pietinen P, Spiegelman D, Stevens J, Virtamo J, Willett WC, Ascherio A: Major types of dietary fat and risk of coronary heart disease: a pooled analysis of 11 cohort studies. Am J Clin Nutr 2009;89:1425-1432.

-9 Mensink RP, Katan MB: Effect of dietary trans fatty acids on high-density and low-density lipoprotein cholesterol levels in healthy subjects. N Engl J Med 1990;323:439-445.

10 Mozaffarian D, Katan MB, Ascherio A, Stampfer MJ, Willett WC: Trans fatty acids and cardiovascular disease. $\mathrm{N}$ Engl $\mathrm{J}$ Med 2006;354:1601-1613.

11 Skeaff CM, Miller J: Dietary fat and coronary heart disease: summary of evidence from prospective cohort and randomised controlled trials. Ann Nutr Metab 2009;55:173201.

12 Elmadfa I, Kornsteiner M: Dietary fat intake a global perspective. Ann Nutr Metab 2009; 54(suppl 1):8-14.

13 Massart DL, Vandeginste BGM, Buydens LMC, de Jong S, Lewi PJ, Smeyers-Verbeke J: Handbook of Chemometrics and Qualimetrics: Part A. Amsterdam, Elsevier, 1997.

14 Australian Bureau of Statistics: National Nutrition Survey: Nutrient Intakes and Physical Measurements, Australia 1995. Canberra, AGPS, 1998.

15 Elmadfa I, Freisling H, Nowak V, Hofstädter D, et al: Österreichischer Ernährungsbericht, 1 Auflage, Wien, März 2009.

16 Chen Y, Ahsan H, Parvez F, Howe GR: Validity of a food-frequency questionnaire for a large prospective cohort study in Bangladesh. Br J Nutr 2004;92:851-859.

17 Voedselconsumptiepeiling: De Belgische Voedselconsumptiepeiling 1-2006. Brussel, Afdeling Epidemiologie, 2006.

18 Stekka P: Dietary and nutritional status survey of the population in Bulgaria; in Stekka Petrova (ed): National Center of Hygiene, Medical Ecology and Nutrition, 1998, pp 98121.
19 Mennen LI, Mbanya JC, Cade J, Balkau B, Sharma S, Chungong S, Cruickshank JK: The habitual diet in rural and urban Cameroon. Eur J Clin Nutr 2000;54:150-154.

20 Health Canada: Canadian community health survey cycle 2.2, nutrition (2004). Nutrient intakes from food. Ontario, Health Canada Ottawa, 2004.

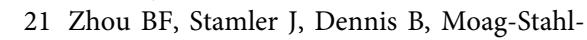
berg A, Okuda N, Robertson C, Zhao L, Chan Q, Elliott P: Nutrient intakes of middle-aged men and women in China, Japan, the United Kingdom, and United States in the late 1990s: the INTERMAP study. J Hum Hypertens 2003; 17:623-630.

22 Boylan S, Welch A, Pikhart H, Malyutina S, Pajak A, Kubinova R, Bragina O, Simonova G, Stepaniak U, Gilis-Januszewska A, Milla L, Peasey A, Marmot M, Bobak M: Dietary habits in three central and eastern European countries: the HAPIEE study. BMC Public Health 2009;9:439.

23 DTU Fødevareinstituttet 2010: Dietary Habits in Denmark 2003-2008.

24 Paturi M, Tapanainen H, Reinivuo H, Pietinen P (eds): The National FINDIET 2007 Survey. KTL-National Public Health Institute, 2007. http://www.ktl.fi/attachments/suomi/ julkaisut/julkaisusarja_b/2008/2008b23.pdf.

25 Credoc: Comportements et consommations alimentaires en France. http://www.credoc. fr/departements/conso.php.

26 Max Rubner-Institut (eds): Nationale Verzehrsstudie II. Ergebnisbericht Teil 1. Die bundesweite Befragung zur Ernahrung von Jugendlichen und Erwachsenen. Karlsruhe, 2008.

27 Elmadfa I, Weichselbaum E, Koning J, Remaut der Winter A-M, Haapala I, Uustalo U, Mennen L, Hercberg S, Wolfram G, Trichopoulou A, et al: European Nutrition and Health Report 2004. Forum of Nutrition. Basel, Karger, 2005.

28 Gregory CO, McCullough ML, Ramirez-Zea M, Stein AD: Diet scores and cardio-metabolic risk factors among Guatemalan young adults. Br J Nutr 2009;101:1805-1811.

29 Woo J, Leung SSF, Ho SC, Sham A, Lam TH, Janus ED: Dietary practices and lipid intake in relation to plasma lipid profile in Hong Kong Chinese. Eur J Clin Nutr 1997;51:467-471.

30 Szeitz-Szabo M, Biro L, Biro G, Sali J: Dietary Survey in Hungary, 2009. Part I. Macronutrients, alcohol, caffeine, fibre. Acta Aliment 2011;40:142-152.

31 Sudha V, Radhika G, Sathya RM, Ganesan A, Mohan V: Reproducibility and validity of an interviewer-administered semi-quantitative food frequency questionnaire to assess dietary intake of urban adults in southern India. Int $J$ Food Sci Nutr 2006;57:481-493.

32 Djuwita-Hatma R, Lukito W, Rumawas YSP: Fatty acids intake among diverse ethnic groups in Indonesia. Med J Indones 2005; 14:242-248.

33 Joyce T, Wallace AJ, McCarthy SN, Gibney MJ: Intakes of total fat, saturated, monounsaturated and polyunsaturated fatty acids in
Irish children, teenagers and adults. Public Health Nutr 2009;12:156-165.

34 Food \& Nutrition Services: MABAT First Israeli National Health and Nutrition Survey 1999-2001. Israel Centre for Disease Control, Ministry of Health, 2003.

35 D Amicis A: Il quadro nutrizionale della popolazione in Italia. Riv Sci Alim 2000;29:7-11.

36 Muramatsu K, Tsuchihashi N, Tanaka E, Yamaguchi M, Suzuki A, Ishii K, Watanabe T: Estimated intake of cholesterol and fatty acids in Japanese. Bull Chiba Coll Health Sci 2004; 23:1-25.

37 Eng JY, Moy FM: Validation of a food frequency questionnaire to assess dietary cholesterol, total fat and different types of fat intakes among Malay adults. Asia Pac J Clin Nutr 2011;20:639-645.

38 Ramirez-Silva I, Villalpando S, Moreno-Saracho JE, Bernal-Medina D: Fatty acids intake in the Mexican population. Results of the National Nutrition Survey 2006. Nutr Metab (Lond) 2011;8:33.

39 van Rossum CTM, Fransen HP, VerkaikKloosterman J, Buurma-Rethans EJM, Ocke MC: Dutch National Food Consumption Survey 2007-2010. Diet of children and adults aged 7 to 69 years. Bilthoven, National Institute for Public Health and the Environment, 2011.

40 University of Otago and Ministry of Health: A focus on nutrition: key findings of the 2008/09 New Zealand Adult Nutrition Survey; Wellington, Ministry of Health, 2011.

41 Johansson L, Solvoll K: Norkost 1997. Rapport nr 2/1999. Statens råd for ernæring og fysisk aktivitet.http://www.shdir.no/vp/multimedia/ archive/00003/IS-0168_3745a.pdf.

42 Szponar L, Sekula W, Oltarzewski M, Katarzyna F: Household food consumption and anthropometric survey, National Food and $\mathrm{Nu}$ trition Institute, 2003.

43 Graca P: Dietary guidelines and food nutrient intakes in Portugal. Br J Nutr 1999;81(suppl 2): S99-S103.

44 Health Promotion Board: Report of the National Nutritional Survey Singapore. http:// www.hpb.gov.sg/data/hpb.home/files/edu/ NNS\%20Report_Final(Merged).pdf.

45 Babinska K, Bederova A: Changes in nutrient intake in the adult population of the Slovak Republic. J Food Compost Anal 2002;15:359365.

46 Koch V, Pokom D: Comparison of nutritional habits among various adult age groups in Slovenia. Nutr Res 1999;19:1153-1164.

47 MacIntyre UE, Kruger HS, Venter CS, Vorster HH: Dietary intakes of an African population in different stages of transition in the North West Province, South Africa: the THUSA study. Nutr Res 2002;22:239-256.

48 Kim J, Kim YJ, Ahn YO, Paik HY, Ahn Y, Tokudome Y, Hamajima N, Inoue M, Tajima $\mathrm{K}$ : Contribution of specific foods to fat, fatty acids, and cholesterol in the development of a food frequency questionnaire in Koreans. Asia Pac J Clin Nutr 2004;13:265-272. 
49 Becker W, Pearson M: Kostvanor och näringsintag i Sverige. Riksmaten 1997-98. Livsmedelsverket. http://www.slv.se/upload/ dokument/rapporter/kostundersokningar/ riksmat.pdf.

50 Pot GK, Prynne CJ, Roberts C, Olson A, Nicholson SK, Whitton C, Teucher B, Bates B, Henderson H, Pigott S, Swan G, Stephen AM: National Diet and Nutrition Survey: fat and fatty acid intake from the first year of the rolling programme and comparison with previous surveys. Br J Nutr 2012;107:405415.

51 NHANES 2010: What we eat in America. NHANES 2007-2008.

-52 Meyer BJ, Mann NJ, Lewis JL, Milligan GC, Sinclair AJ, Howe PR: Dietary intakes and food sources of omega- 6 and omega- 3 polyunsaturated fatty acids. Lipids 2003;38:391-398.

53 Sioen I, Vyncke K, De MM, Gerichhausen M, De HS: Dietary intake and food sources of total and individual polyunsaturated fatty acids in the Belgian population over 15 years old Lipids 2013;48:729-738.

54 Sioen I, Vyncke K, De Maeyer M, Gerichhausen $M$, De Henauw S: Dietary intake and food sources of omega- 6 and omega- 3 polyunsaturated fatty acids in Belgian adults (poster presentation). Brussels, Belgian Conference, 2012.

55 Ernahrungbericht: Deutsche Gesellschaft fur Ernahrung E.V. Bonn, 2004. www.dge.de.

-56 Hulshof KF, van Erp-Baart MA, Anttolainen M, Becker W, Church SM, Couet C, Hermann-Kunz E, Kesteloot H, Leth T, Martins I, Moreiras O, Moschandreas J, Pizzoferrato L, Rimestad AH, Thorgeirsdottir H, van Amelsvoort JM, Aro A, Kafatos AG, Lanzmann-Petithory D, van PG: Intake of fatty acids in Western Europe with emphasis on trans fatty acids: the TRANSFAIR Study. Eur J Clin Nutr 1999;53:143-157.
57 Linseisen J, Welch AA, Ocke M, Amiano P, Ag noli C, Ferrari P, Sonestedt E, Chajes V, Buenode-Mesquita HB, Kaaks R, Weikert C, Dorronsoro M, Rodriguez L, Ermini I, Mattiello A, van der Schouw YT, Manjer J, Nilsson S, Jenab M, Lund E, Brustad M, Halkjaer J, Jakobsen MU, Khaw KT, Crowe F, Georgila C, Misirli G, Niravong $\mathrm{M}$, Touvier M, Bingham S, Riboli E, Slimani N: Dietary fat intake in the European Prospective Investigation into Cancer and $\mathrm{Nu}$ trition: results from the 24-hour dietary recalls. Eur J Clin Nutr 2009;63(suppl 4):S61-S80.

58 Willett WC: Is dietary fat a major determinant of body fat? Am J Clin Nutr 1998;67:556S$562 \mathrm{~S}$.

59 Biro G, Hulshof KF, Ovesen L, morim Cruz JA: Selection of methodology to assess food intake. Eur J Clin Nutr 2002;56(suppl 2):S25-S32.

60 Nelson M: Methods and validity of dietary assessment; in Garrow JS et al (eds): Human Nutrition and Dietetics. Edinburgh, Churchill Livingstone, 2000, pp 311-329.

61 Burlingame BA, Charrondiere UR: FAO: food composition data, production, management and use. Rome, Food and Agriculture Organization of the United Nations, 2003.

62 Russell D, Parnell W, Wilson N: NZ food: NZ people. Key results of the 1997 National Nutrition Survey. Ministry of Health Wellington, New Zealand, 1999.

63 Gregory J, Lowe S, Bates JC, Prentice A, Jackson LV, Smithers G, Wenlock R, Farron M: The National Diet and Nutrition Survey: young people aged $4-18$ years. London: The Stationary Office, 2000.

64 Ghafoorunissa: Fats in Indian diets and their nutritional and health implications. Lipids 1996;31(suppl):S287-S291

65 Shetty PS: Nutrition transition in India. Public Health Nutr 2002;5:175-182.

66 Harika RK, Cosgrove MC, Osendarp SJ, Verhoef P, Zock PL: Fatty acid intakes of children and adolescents are not in line with the dietary intake recommendations for future cardiovascular health: a systematic review of dietary intake data from thirty countries. Br J Nutr 2011;106:307-316.
67 Razanamahefa L, Lafay L, Oseredczuk M, Thiebaut A, Laloux L, Gerber M, Astorg P, Berta JL: Dietary fat consumption of the French population and quality of the data on the composition of the major food groups. Bull Cancer 2005;92:647-657.

68 Linseisen J, Bergstrom E, Gafa L, Gonzalez CA, Thiebaut A, Trichopoulou A, Tumino R, Navarro SC, Martinez GC, Mattisson I, Nilsson S, Welch A, Spencer EA, Overvad K, Tjonneland A, Clavel-Chapelon F, Kesse E, Miller AB, Schulz M, Botsi K, Naska A, Sieri S, Sacerdote C, Ocke MC, Peeters PH, Skeie G, Engeset D, Charrondiere UR, Slimani N: Consumption of added fats and oils in the European Prospective Investigation into Cancer and $\mathrm{Nu}$ trition (EPIC) centres across 10 European countries as assessed by 24-hour dietary recalls. Public Health Nutr 2002;5:1227-1242.

69 Zatonski WA, Willett W: Changes in dietary fat and declining coronary heart disease in Poland: population based study. BMJ 2005; 331:187-188

70 Pietinen P, Vartiainen E, Seppanen R, Aro A, Puska P: Changes in diet in Finland from 1972 to 1992: impact on coronary heart disease risk. Prev Med 1996;25:243-250.

71 Katan MB, Grundy SM, Willett WC: Should a low-fat, high-carbohydrate diet be recommended for everyone? Beyond low-fat diets. N Engl J Med 1997;337:563-566.

72 Willett WC, Leibel RL: Dietary fat is not a major determinant of body fat. Am J Med 2002; 113(suppl 9B):47S-59S.

$\checkmark 73$ Gifford KD: Dietary fats, eating guides, and public policy: history, critique, and recommendations. Am J Med 2002;113(suppl 9B): 89S-106S.

74 FAO/WHO: Report of a joint WHO/FAO expert consultation. Diet, nutrition and prevention of chronic diseases. Geneva, World Health Organization, 2003. 